\title{
Antiprogestins in Ovarian Cancer
}

\author{
Carlos M. Telleria and Alicia A. Goyeneche \\ Division of Basic Biomedical Sciences, \\ Sanford School of Medicine, \\ The University of South Dakota, Vermillion, South Dakota \\ USA
}

\section{Introduction}

The overall goal of this chapter is to provide evidence for the feasibility of repositioning antiprogestin compounds originally utilized for reproductive medicine toward ovarian cancer therapy. This disease is the most deadly of the female reproductive track; at the time of diagnosis, in the majority of cases abnormal growths have progressed outside the ovaries and into the nearby fallopian tubes, uterus, and peritoneal cavity. Thus, the majority of diagnosed patients require cytoreductive surgery followed by platinum-based chemotherapy (Bukowski et al.,2007; DiSaia\&Bloss,2003; Martin,2007; Naora\&Montell,2005; Ozols,2006a). The efficacy of this therapy, however, is limited by the elevated toxicity of the platinum derivatives (Cepeda et al.,2007), the development of mechanisms to escape drug toxicity (Cepeda et al.,2007; Kelland,2007), and the repopulation or regrowth of cells between treatment intervals (Kim\&Tannock,2005), all of which lead to the recurrence of the disease. The majority of relapsing patients are platinum-resistant, with very limited chemotherapeutic options, and a median survival time of about only two years (Gordon et al.,2004; Modesitt\&Jazaeri,2007; Ozols,2006b; Pectasides et al.,2006; Wilailak\&Linasmita,2004). The five-year survival for ovarian cancer patients is extremely disappointing, ranging from $37 \%$ to $45 \%$ (Jemal et al.,2006). Hence, new therapeutic interventions to overcome the limitations of platinum-based therapy for ovarian cancer patients are greatly needed.

\section{Mifepristone: A prototypical antiprogestin}

The synthetic steroid RU-38486 or simply RU-486, now named mifepristone, was first synthesized in the mid-1980s when investigators were in the pursuit of synthesizing an antiglucocorticoid agent to treat Cushing's syndrome (Spitz,2006); however, because in preclinical studies with pregnant animals the compound had a remarkable capacity to interrupt pregnancy, its ability to oppose progesterone action in the uterus was inferred. As a result, mifepristone was rapidly repositioned for reproductive medicine, to exploit largely its antiprogesterone and, consequently, contraceptive properties. Mifepristone became the first prototypical antiprogestin clinically approved for early termination of pregnancy in the United States in 2000. In this context, mifepristone blocks progesterone receptors in the uterus (Philibert et al.,1985), thus increasing the sensitivity to myometrial contractions induced by prostaglandin analogues, leading to early interruption of pregnancy (Benagiano et al.,2008a). 
Mifepristone has also been used for other reproductive indications, such as oral contraception, menstrual regulation, and emergency contraception (Benagiano et al.,2008b; Ho et al.,2002). More recently, mifepristone emerged as a treatment of endocrine-related diseases such as endometriosis and uterine leiomyoma (Moller et al.,2008); it diminishes the pain associated with pelvic endometriosis (Fedele\&Berlanda,2004; Kettel et al.,1994) and reduces the size of uterine fibroids, improving quality of life without evidence of endometrial hyperplasia (Eisinger et al.,2009; Murphy et al.,1995; Steinauer et al.,2004).

\section{Mifepristone is a valuable therapeutic alternative in oncology}

The antiprogestin activity of mifepristone has been extensively studied; however, it is evident that the contraceptive effect of the compound jeopardized its investigation for other medical uses, in particular, its application in oncology, which is now emerging. In nonreproductive tissues, it was reported that mifepristone inhibited the growth of gastric cancer cells (Li et al.,2004), meningioma cells in vitro and in vivo (Grunberg et al.,2006; Grunberg et al.,1991; Matsuda et al.,1994; Tieszen et al.,2011), glioblastoma and osteosarcoma cells (Tieszen et al.,2011), and non-small lung cell carcinoma cell lines (Weidner, Hapon \& Telleria, unpublished observations).

In reproductive tissues, mifepristone blocked the growth of cervical adenocarcinoma cells in vitro and in vivo (Jurado et al.,2009), and inhibited cell proliferation killing benign and malignant endometrial cancer cells (Han\&Sidell,2003; Murphy et al.,2000; Narvekar et al.,2004; Schneider et al.,1998). In prostate cancer, the antiprogestin blocked growth of androgen-sensitive and androgen-insensitive LNCaP and PC-3 cells (El Etreby et al.,2000a; El Etreby et al.,2000b; Liang et al.,2002; Tieszen et al.,2011). In breast cancer, mifepristone inhibited the growth of T-47D (Musgrove et al.,1997), MCF-7, and MDA-MB-231 cells (Tieszen et al.,2011); particularly in MCF-7 cells, mifepristone had an additive lethal effect when associated with the antiestrogen tamoxifen (El Etreby et al.,1998), as well as a synergistic lethal interaction with the Chk-1 inhibitor 7-hydroxystaurosporine (UCN-01) (Yokoyama et al.,2000) and with 4-hydroxytamoxifen (Schoenlein et al.,2007). Mifepristone also blocked the growth of MCF-7 sublines made resistant to 4-hydroxytamoxifen (Gaddy et al.,2004) and was lethal to MDA-MB-231 cells that are devoid of estrogen and progesterone receptors (Liang et al.,2003). In p53/BRCA1-deficient mice, mifepristone prevented the formation of breast tumors (Poole et al.,2006), indicating its efficacy not only impairing the growth of established mammary tumors but also inhibiting mammary tumorigenesis. In mice with spontaneous lung cancer or leukemia, mifepristone was also found to improve longevity and quality of life (Check et al.,2009; Check et al.,2010b). Most recently, case studies of patients with widely metastatic thymic, renal, colon, or pancreatic cancers no longer responding to chemotherapy, reported that chronic daily treatment with $200 \mathrm{mg}$ mifepristone had a significant improvement in their qualities of life (Check et al.,2010a).

\section{Mifepristone in ovarian cancer therapeutics}

The action of antiprogestins on ovarian cancer has received limited attention. First in 1996, it was revealed that the antiprogestin mifepristone arrested OVCAR-3 and A2780 ovarian cancer cells at the G1 phase of the cell cycle (Rose\&Barnea,1996). In a small clinical trial conducted with patients having recurrent epithelial ovarian cancer whose tumors had become resistant to standard chemotherapy, mifepristone administration showed promising 
effects against some of the tumors (Rocereto et al.,2000). Years later, it was reported that mifepristone enhanced the toxic effect of cisplatin on COC1 ovarian cancer cells in vitro and in xenografted immunosuppressed mice (Liu et al.,2003; Qin\&Wang,2002).

These initial studies indicated an anti-ovarian cancer activity of mifepristone, yet the molecular target(s) involved in mediating such an effect remained obscure. In 2007, we described some molecular mediators of growth inhibition induced by mifepristone as a single agent in ovarian cancer cells, and further defined its efficacy in an in vivo preclinical setting (Goyeneche et al.,2007). We also proved that cytostatic doses of mifepristone added after a lethal dose of cisplatin prevents repopulation of remnant ovarian cancer cells surviving a platinum insult (Freeburg et al.,2009b). We showed that cell cultures exposed to mifepristone after cisplatin had a remarkable increase in the percentage of cells expressing the cell death marker cleaved poly (ADP-ribose) polymerase (PARP) and the mitotic marker phospho-histone $\mathrm{H} 3$ suggesting that mifepristone potentiates cisplatin lethality and that the cells likely die as a consequence of mitotic failure (Freeburg et al.,2009b). We also reported that the effect of mifepristone in ovarian cancer cells is independent of p53 functionality and platinum sensitivity (Freeburg et al.,2009a), making mifepristone an even more interesting chemotherapeutic candidate for ovarian cancer as the majority of tumors in relapsing patients are platinum resistant and p53 mutant (Ozols,2006b). Finally, we have shown in ovarian cancer cells that mifepristone potentiates the lethality of otherwise sub-lethal doses of cisplatin, and synergizes with cisplatin growth inhibiting ovarian cancer cells of different genetic backgrounds and platinum sensitivities (Gamarra-Luques\&Telleria,2010).

\subsection{Mifepristone-induced cytostasis vs. lethality in ovarian cancer cells}

Antiprogestin mifepristone is toxic towards ovarian cancer cells, with cytostasis manifested at lower micromolar concentrations and lethality taking place when the compound is used at higher micromolar doses (Freeburg et al.,2009a; Goyeneche et al.,2007; Goyeneche et al.,2011; Tieszen et al.,2011). When mifepristone was used at doses up to $20 \mu \mathrm{M}$, the effect was limited to cytostasis demonstrated by the reversibility of the growth inhibition observed when the drug was removed from the culture media, in association with the lack of measurable cell death (Goyeneche et al.,2007). In all ovarian cancer cell lines we investigated, concentrations of mifepristone $30 \mu \mathrm{M}$ or higher were lethal (Freeburg et al.,2009a; Goyeneche et al.,2011; Tieszen et al.,2011). This lethality was illustrated by the reduced viability of the cells, the increase in cellular particles with hypodiploid fragmented DNA content, and the cleavage of the cell death associated caspase, caspase-3, in parallel with the cleavage of the widely accepted marker of cell death and a substrate for caspase-3, PARP (Scovassi\&Poirier,1999). The lethality of concentrations of mifepristone over $40 \mu \mathrm{M}$ towards ovarian cancer cells was first suggested in OVCAR-3 and A2780 cells (Rose\&Barnea,1996). Yet, our studies demonstrate that the lethality of mifepristone monotherapy towards ovarian cancer cells is related to a caspaseassociated apoptotic process.

The dose-dependent cytostatic and lethal effects of mifepristone towards ovarian cancer cells, which we globally refer to as cytotoxicity, occur also in breast cancer cells. In the MCF7 breast cancer cell line the combination of mifepristone and antiestrogen 4hydroxytamoxifen had greater cytostatic and lethal activities than either monotherapy, whereas the lethality of the treatment was associated with genomic DNA fragmentation and cleavage of PARP (Schoenlein et al.,2007). In addition, it has been shown that MCF-7 cells made resistant to 4-hydroxytamoxifen also respond to mifepristone monotherapy undergoing apoptotic death (Gaddy et al.,2004); finally, although at higher concentrations, 
mifepristone was also cytotoxic to progesterone receptor- and estrogen receptor-negative MDA-MB-231 breast cancer cells (Liang et al.,2003; Tieszen et al.,2011).

\subsection{The inhibition of ovarian cancer growth by mifepristone occurs regardless of histopathological classification, platinum sensitivity, or p53 genetic background}

Ovarian cancer is very heterogeneous from histopathological and genetic viewpoints (Cannistra,2004; Despierre et al.,2010). Furthermore, mutations of the p53 tumor suppressor gene occur at extremely high frequencies in ovarian cancer (Havrilesky et al.,2003), whereas most recurrent patients with ovarian cancer are platinum-resistant, consequently being left with therapeutic alternatives that have very disappointing outcomes (DiSaia\&Bloss,2003; Herzog,2006; Vasey,2003). Thus, if the histopathological and genetic backgrounds, sensitivity to platinum, and p53 status of the ovarian cancer cells would not condition their response to the growth inhibition activity of mifepristone, such findings would have pronounced clinical relevance.

We showed that the cytostatic effect of mifepristone displayed similar potency among the ovarian cancer cells representing various histopathological origins (Freeburg et al.,2009a; Goyeneche et al.,2007; Tieszen et al.,2011), such as clear cell adenocarcinoma (SK-OV-3), papillary ovarian adenocarcinoma (Caov-3 cells), glandular with mixed differentiation (IGROV-1), undifferentiated (A2780), and endometrioid (OV2008) cells (Shaw et al.,2004).

We proved that the growth inhibition induced by mifepristone occurred irrespective of the p53 background of the ovarian cancer cell lines studied, with $\mathrm{IC}_{50 \text { s }}$ ranging between $\sim 7$ to 12 $\mu \mathrm{M}$ (Freeburg et al.,2009a; Goyeneche et al.,2007) in p53 wild type cells [e.g. OV2008, OV2008/C13, A2780, and IGROV-1; (Casalini et al.,2001; Fraser et al.,2003; Sasaki et al.,2000; Siddik et al.,1998)], p53 mutant cells [A2780/CP70 and Caov-3 (Lu et al.,2001; Reid et al.,2004; Yaginuma\&Westphal,1992)], or p53 null cells [SK-OV-3; (O'Connor et al.,1997; Yaginuma\&Westphal,1992)].

We observed that mifepristone displayed similar growth inhibition potency among SK-OV3, OV2008, and Caov-3 cell lines (Goyeneche et al.,2007), which have different sensitivities to platinum agents. OV2008 cells were reported as being highly sensitive to cisplatin (Katano et al.,2002), SK-OV-3 cells were originally obtained from a patient with intrinsic resistance to clinically achievable doses of cisplatin and considered, in vitro, as semi-resistant to platinum (Ormerod et al.,1996), whereas Caov-3 cells were shown to be resistant to cisplatin (Arimoto-Ishida et al.,2004; Hayakawa et al.,1999). Furthermore, when we studied the action of mifepristone among ovarian cancer cell line pairs consisting of cisplatinsensitive parental lines and stable cisplatin-resistant sublines derived by in vitro selection with stepwise exposure to cisplatin, the toxicity of mifepristone did not discriminate among the cell lines, as we could not find a correlation between the $\mathrm{IC}_{50 \mathrm{~s}}$ for mifepristone and the $\mathrm{IC}_{50 \mathrm{~s}}$ for cisplatin obtained for the ovarian cancer cell lines studied (Freeburg et al.,2009a). These results confirm that mifepristone growth inhibits ovarian cancer cells regardless of their sensitivities to cisplatin.

\section{Anti-ovarian cancer effect of antiprogestins other than mifepristone: ORG- 31710 and CDB-2914 (Ulipristal)}

ORG-31710 and CDB-2914 (a.k.a. ulipristal) are two members of a family of selective progesterone receptor modulators with a similar structure to RU-38486, as they all contain a dimethylaminophenyl substitution at the $11 \beta$-position that confers antiprogestin activity 
(Belanger et al.,1981; Benagiano et al.,2008a; Moller et al.,2008) (Fig. 1). ORG-31710 and CDB2914, however, were designed with the aim to decrease the antagonistic effect of RU-38486 on the glucocorticoid receptor by substitutions made at the $17 \alpha$ side chain (Moller et al.,2008).

Mifepristone (RU-38486)

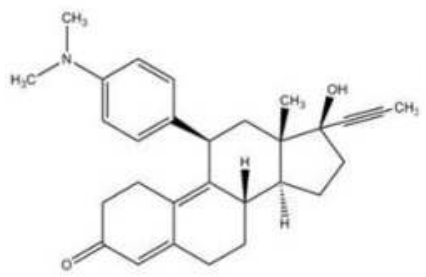

Ulipristal (CDB-2914)

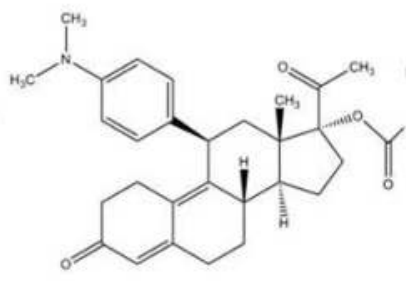

ORG-31710

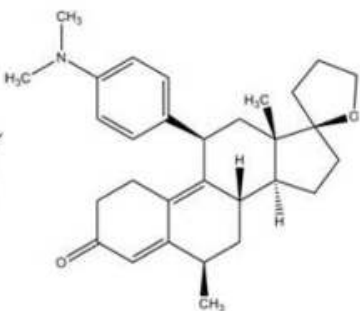

Fig. 1. Chemical structure of antiprogestins [Adapted from (Goyeneche et al.,2011)]

Limited information is available on the oncologic value of CDB-2914 and ORG-31710. Both chemicals were effective in rats, reducing the growth of established DMBA-induced breast tumors (Kloosterboer et al.,2000; Wiehle et al.,2007). In cultured human uterine leiomyoma cells, CDB-2914 inhibited cell proliferation down-regulating PCNA expression and inducing apoptosis ( $\mathrm{Xu}$ et al.,2005). Moreover, a randomized controlled clinical trial revealed that CDB-2914 reduced leiomyoma growth (Levens et al.,2008). ORG-31710, on the other hand, was effective in increasing apoptosis in human periovulatory granulosa cells (Svensson et al.,2001). We have proved that mifepristone, ORG-31710 and CDB-2914, are all cytostatic at lower concentrations and lethal at higher doses towards OV2008 and SK-OV-3 ovarian cancer cells (Goyeneche et al.,2011).

\section{Mechanisms of antiproliferation of ovarian cancer cells by antiprogestins}

It is apparent that different antiprogestin compounds are cytotoxic to ovarian cancer cells displaying two main effects: (i) a cytostatic effect at lower concentrations blocking cell growth at the G1 phase of the cell cycle; and (ii) a lethal effect at higher doses associated with morphological features of apoptosis and fragmentation of the genomic DNA. The overall toxicity of antiprogestins involves a dose-dependent decline in the activity of the cell cycle regulatory protein cyclin dependent kinase 2 (Cdk-2).

\subsection{Cell cycle arrest}

Exposure of ovarian cancer cells to concentrations of mifepristone likely to be achieved in vivo inhibits their growth by inducing G1 cell cycle arrest without triggering cell death. This is consistent with the dose-dependent tumor growth inhibition achieved by mifepristone monotherapy in vivo in nude mice carrying subcutaneous tumors derived from human ovarian cancer cells (Goyeneche et al.,2007).

The growth inhibitory effect of mifepristone on ovarian cancer cells is associated with inhibition of DNA synthesis, down-regulation of the transcription factor E2F1 needed for $S$ phase progression, and inhibition of the activity of Cdk-2. This cell cycle regulatory protein is critical to promote the transition of cells in the cell cycle from G1 to $S$ phase (Conradie et al.,2010). For instance, the activity of Cdk-2 is needed for the stimulation of 
histone gene transcription (Zhao et al.,2000), which is one of the major events marking the entry into the $S$ phase. To drive cell cycle progression, Cdk-2 should be free of p21cip1 and p27kip1 binding (Conradie et al.,2010), bound to cyclin E, and allocated to the nucleus to phosphorylate cell cycle regulatory proteins (Brown et al.,2004; Lents et al.,2002). Mifepristone, ORG-31710 and CDB-2914 affect the nucleocytoplasmic trafficking of Cdk inhibitors p21 cip1 and p27kip1, Cdk-2 and its co-factor cyclin E. The antiprogestins also increase p21 ${ }^{\text {cip } 1}$ and p27kip1 abundances in both cytoplasm and nuclear compartments in correlation with decreased Cdk-2 and cyclin E nuclear levels, increased cytoplasmic cyclin $\mathrm{E}$, and a remarkable decline in the activity of Cdk-2 in both subcellular compartments (Goyeneche et al.,2007; Goyeneche et al.,2011).

Because Cdk-2 is frequently up-regulated in ovarian tumors as compared to non-cancerous cells (Sui et al.,2001), the potent inhibition of Cdk-2 elicited by antiprogestins may be critically important from a translational therapeutics viewpoint. Moreover, because cytoplasmic localization of $\mathrm{Cdk}$ inhibitor p27kip1 in ovarian cancer patients has been associated with poor prognosis (Rosen et al.,2005), by promoting an increase in p27kip1 in the nucleus, antiprogestins may be able to rescue the tight inhibitory control of Cdk inhibitors on Cdk-2 activity that is mostly lost in ovarian cancer.

The magnitude of inhibition of Cdk-2 activity is related to the growth inhibition potency of the antiprogestins with mifepristone>ORG-31710>CDB-2914 (Goyeneche et al.,2011). Supporting our results, a decline in cyclin E-associated kinase activity (presumably Cdk2) was reported for T-47D breast cancer cells in response to ORG-31710 in the absence of significant changes in cyclin E and Cdk levels, but in the presence of elevated amounts of p21 cip1, suggesting that $\mathrm{p} 21^{\text {cip1 }}$ contributes to the reduction in Cdk-2 activity after antiprogestin treatment (Musgrove et al.,1997). In ovarian cancer cells, we provide evidence that not only the increased association of p21cip1 and p27kip1 to Cdk-2 may account for the reduced Cdk-2 activity in the nucleus in response to antiprogestins, but also a reduction in Cdk-2 and cyclin E nuclear levels and redistribution of cyclin $\mathrm{E}$ to the cytoplasm, are related variables leading to blunt Cdk-2 nuclear activity needed for the cells to transit from G1 to S phase. A recent study using LNCaP prostate cancer cells revealed that targeting Cdk-2 to the nucleus is sufficient to prevent growth inhibition triggered by $1,25(\mathrm{OH})_{2}$ D3 (Flores et al.,2010), suggesting that antiprogestin-mediated growth inhibition and growth arrest triggered by metabolites of vitamin D may share common molecular intermediaries.

\subsection{Cell death}

At high concentrations, the antiprogestins mifepristone, ORG-31710 and CDB-2914 blunt the activity of Cdk-2 leading to ovarian cancer cell death in association with morphological features of apoptosis, hypodiploid DNA content, fragmentation of the DNA, and cleavage of the executer caspase substrate PARP (Goyeneche et al.,2011). Such effects may be the consequence of Cdk-2 inhibition. For instance, in addition to regulating cell cycle progression, Cdk-2 is involved in cell survival after DNA damage (Deans et al.,2006; Huang et al.,2006). As a survival factor, Cdk-2 phosphorylates the FOXO1 transcription activator of pro-apoptotic genes, keeping them in the cytoplasm (Huang et al.,2006; Huang\&Tindall,2007) . If the activity of Cdk-2 is abolished by an antiprogestin, then FOXO1 may not be retained in the cytoplasm, consequently migrating to the nucleus where it promotes the expression of pro-apoptotic genes (Huang et al.,2006; Huang\&Tindall,2007). 
The lethality of high concentration antiprogestins has features of apoptosis similar to that of platinum-induced lethality in the same cell lines in terms of nuclear and DNA fragmentation (Goyeneche et al.,2011); however, the molecular mediators of antiprogestininduced cell death vary among the steroids. Cleavage of the caspase- 3 substrate PARP is a commonality among mifepristone, ORG-31710 and CDB-2914. CDB-2914 also causes an upregulation of PARP which was previously observed in cultured human uterine leiomyoma cells (Xu et al.,2005). In addition, CDB-2914 causes up-regulation of the anti-apoptotic proteins XIAP and Bcl-2, yet cell death still ensues but with less effectiveness than that observed after exposure to high concentrations of mifepristone or ORG-31710, in which both XIAP and Bcl-2 are down-regulated after 3 days of treatment (Goyeneche et al.,2011). Thus, the extended up-regulation of XIAP and Bcl-2 upon CDB-2914 treatment but not after mifepristone or ORG-31710 may account for the reduced cytotoxic potency of CDB-2914. Although with different potencies, high concentrations of antiprogestins lead the cells to cross a cell death threshold or point of no return in which the pro-apoptotic load of the cell surpasses its anti-apoptotic buffering capacity.

\subsection{Progesterone receptors are not essential for the growth arrest induced by antiprogestins in ovarian cancer}

Because several tumors of both gynecologic and non-gynecologic origin are steroid hormone-dependent and express progesterone receptors, antiprogestins have been investigated as potential anti-cancer therapeutic agents largely based on their capacity to modulate progesterone receptors. However, whether the mechanism(s) through which antiprogestins act to induce cytostasis and lethality in cancer cells actually requires progesterone receptor expression remains obscure.

When targeting cancer cells mifepristone has progesterone-like activity. For example, in T47D breast cancer cells and HeLa cervical adenocarcinoma cells, mifepristone induced progesterone-regulated reporter genes mainly when the cyclin AMP pathway was activated (Kahmann et al.,1998; Sartorius et al.,1993). In ovarian cancer cells, progesterone blocked cell growth (Syed\&Ho,2003; Syed et al.,2007; Syed et al.,2001); likewise, mifepristone also induced cell growth arrest, though with greater potency than synthetic progestins (Goyeneche et al.,2007). These data suggest that the cytostatic effect of mifepristone might be mediated by an agonistic action on progesterone receptors.

Nonetheless, there is ample evidence suggesting that the efficacy of antiprogestins as anticancer agents may not require progesterone receptor expression. Liang and colleagues reported that micromolar doses of mifepristone monotherapy were able to inhibit the growth of estrogen receptor- and progesterone receptor-negative MDA-MB-231 breast cancer cells (Liang et al.,2003). In another report mifepristone, instead of blocking growth inhibition induced by progesterone, potentiated progesterone-mediated growth retardation and apoptosis (Moe et al.,2009). Such potentiation of cytotoxicity of progesterone by mifepristone was also observed in progesterone receptor positive MCF-7 breast cancer cells and progesterone receptor negative C4-I cervical carcinoma cells, suggesting that the presence of progesterone receptor is not essential for the anti-growth properties of both progesterone and mifepristone (Fjelldal et al.,2010).

The reported level of expression of progesterone receptors in ovarian cancer cell lines is controversial. Progesterone receptor immuno-reactive proteins A (PR-A) and B (PR-B) were identified in OVCA-429 and OVCA-432 ovarian cancer cells-derived from patients with 
late-state serous ovarian cancer - at levels higher than those found in immortalized human ovarian surface epithelial cells (Mukherjee et al.,2005). Papillary adenocarcinoma Caov-3 ovarian cells were reported to express progesterone receptor mRNA in one study (Akahira et al.,2002) but not in another report (Hamilton et al.,1984). Similarly, studies in clear adenocarcinoma SK-OV-3 ovarian cells showing some and no expression of progesterone receptor mRNA have been published (Hamilton et al.,1984; Keith Bechtel\&Bonavida,2001; McDonnel\&Murdoch,2001). We have found low levels of progesterone receptor immunoreactive proteins in endometrioid OV2008 ovarian cancer cells when compared with MCF-7 breast cancer cells used as positive control (Fig.2A). Moreover, utilizing ten cell lines expanding cancers from the nervous system (meningioma IOMM-Lee cells and glioblastoma U87MG cells), breast (estrogen-responsive MCF-7 and estrogen-unresponsive MDA-MB-231 cells), prostate (androgen-responsive LNCaP and androgen-unresponsive PC-3 cells), bone (osteosarcoma U-2OS and SAOS-2 cells), and ovary (OVCAR-3 and SK-OV-3 cells), and two anti-progesterone receptor antibodies, we failed to detect progesterone receptor immunoreactive proteins in all but MCF-7 cells, yet all cell lines studied were growth inhibited by mifepristone (Tieszen et al.,2011). Even in MCF-7 cells carrying progesterone receptors, mifepristone reduced their expression, further discouraging the role of these nuclear receptors as mediators of the growth inhibitory effect of mifepristone given that the cytostatic property of mifepristone can be maintained long after the receptors are downregulated (Tieszen et al.,2011).

These data rule out progesterone receptors as essential mediators of the growth inhibitory effect of antiprogestins. Mainstream literature on the anti-cancer effect of antiprogestin mifepristone assumes that it acts as a progesterone receptor antagonist, implying that the presence of progesterone receptors in the target tissues is a pre-requisite for mifepristone's anti-growth activity. Our work challenges such a dogma (Tieszen et al.,2011), opening the field of study to alternate, non-classical mechanisms whereby antiprogestins operate as cell growth inhibitors without the necessity of nuclear progesterone receptors being present or operational. If these results were translated into the clinic, the presence or absence of classical, nuclear progesterone receptors would not be relevant and would not impact the usage of this drug for cancer therapy.

\subsection{Glucocorticoid receptors and the growth inhibitory activity of antiprogestins}

Antiprogestins, mainly mifepristone, may drive their anticancer action through glucocorticoid receptors. This is because: (i) mifepristone can bind to glucocorticoid receptors with an affinity similar to that of progesterone receptors (Mao et al.,1992); and (ii) ovarian cancer cells have been reported to express glucocorticoid receptors (Tieszen et al.,2011; Xu et al.,2003). In this regard, we have detected abundant levels of glucocorticoid receptor immuno-reactive proteins alpha $(\mathrm{GR} \alpha)$ and beta (GR $\beta$ ) in SK-OV-3, OVCAR-3, and OV2008 cells [(Tieszen et al.,2011) and (Fig.2B)]. When we cultured OV2008 cells in the presence of the glucocorticoid agonist dexamethasone at concentrations equimolar to cytostatic mifepristone, ORG-31710 or CDB2914, however, the antiprogestins up-regulated Cdk inhibitors p21 ${ }^{\text {cip } 1}$ and p27kip1 and blocked cell growth, but dexamethasone did not, though its activity is demonstrated by the downregulation of glucocorticoid receptors (Fig.2B). These data suggest that even if antiprogestins bind glucocorticoid receptors in the ovarian cancer cells, they may not trigger receptor transactivation. Supporting our observations with ovarian cancer cells, mifepristone blocked the growth of LNCaP prostate cancer cells that were either androgen-sensitive or -refractory, while competition for glucocorticoid receptors with equimolar doses of mifepristone and 
hydrocortisone could not reverse the degree of growth inhibition achieved by mifepristone alone (El Etreby et al.,2000b).

A

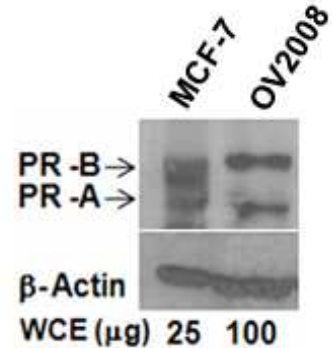

B
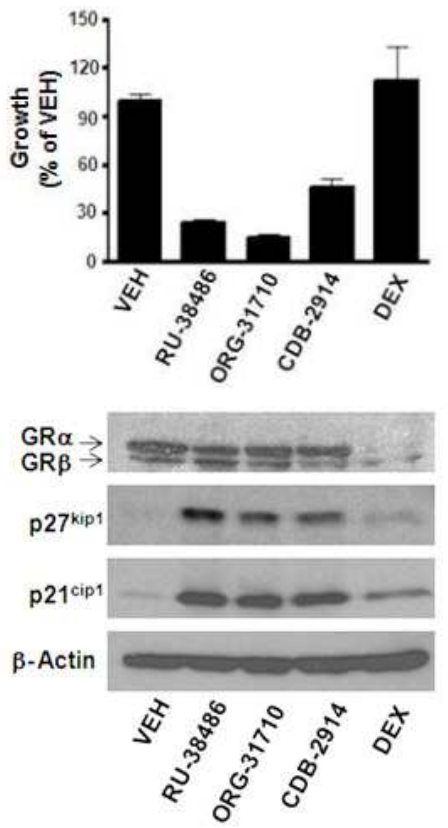

Fig. 2. (A) Expression of progesterone receptor isoforms (PR-A and PR-B) and glucocorticoid receptors (GR $\alpha$ and GR $\beta$ ) in OV2008 ovarian cancer cells. Whole cell extracts (WCE) from MCF-7 cells were used as positive control for progesterone receptor expression. To detect progesterone receptor proteins in OV2008 cells, we worked with cells growing exponentially and increased the WCE loading 4-fold with respect to MCF-7. (B) Effect of equimolar concentrations of antiprogestins and dexamethasone (DEX) on OV2008 ovarian cancer growth. Cells were exposed to vehicle (VEH), $20 \mu \mathrm{M}$ mifepristone (RU-38486), ORG-31710, CDB-3914 (ulipristal) or DEX for $72 \mathrm{~h}$. Cell growth (B, upper panel) was analyzed by microcytometry and protein expression $(B$, lower panel) by Western blot. Bars, mean \pm SEM.

Mifepristone has potent anti-glucorticoid activity (Baulieu,1991; Benagiano et al.,2008c) . Indeed mifepristone binds GR $\alpha$ with mostly antagonistic activity; yet it may have agonistic 
potency depending on the concentration of glucocorticoid receptors in the cell (Zhang et al.,2007). Although GR $\beta$ has been considered a dominant-negative regulator of GR $\alpha$ (Oakley et al.,1999; Taniguchi et al.,2010; Yudt et al.,2003), it was also reported that mifepristone was the only compound of 57 potential natural and synthetic ligands to bind the GR $\beta$ receptor isoform, and that interaction of GR $\beta$ with mifepristone led to its nuclear translocation (Lewis-Tuffin et al.,2007). This latter study also found that despite its classification as a dominant-negative isoform lacking transcriptional activity, GR $\beta$ was able to regulate gene expression in the absence of $G R \alpha$, and this activity was modulated by the interaction with mifepristone. A more recent study also reported intrinsic transcriptional activity of GR $\beta$ independent of GR $\alpha$, but neither found an association between mifepristone binding and nuclear translocation of GR $\beta$, nor could detect modulation of GR $\beta$ transcriptional activity by mifepristone (Kino et al.,2009), adding controversy to the actual activity of mifepristone on GR $\beta$. This evidence and our results encourage performing more studies to underscore a role, if any, for either isoform of the glucocorticoid receptor on the anti-growth activity of the antiprogestin mifepristone.

\subsection{Other potential targets of antiprogestins when operating as cell growth inhibitors}

A possibility exists that antiprogestins may have an effect that does not involve specific hormone receptors. In this regard, mifepristone was shown to have a potent antioxidant activity reflected at micromolar concentrations and likely caused by the dimethylamino phenyl side chain of the molecule (Parthasarathy et al.,1994). Furthermore, the growth inhibitory action of mifepristone in endometrial cells and macrophages was attributed, at least in part, to the antioxidant property of the compound (Murphy et al.,2000; Roberts et al.,1995). A putative antioxidant effect of mifepristone on ovarian cancer cells could be interesting in the context of G1 arrest associated with p21 cip1 upregulation, because p21 cip1 can be induced in response to some antioxidants in a p53 independent manner (Liberto\&Cobrinik,2000; Liu et al.,1999). We have shown that growth arrest caused by mifepristone is associated with p21 cip1 increase in p53 wild type OV2008 cells and in p53 null SK-OV3 cells, opening the possibility for mifepristone acting as an antioxidant to drive G1 arrest through a p53-independent up-regulation of p21cip1.

Another potential target of antiprogestin action is the ubiquitin-proteasome system (UPS). This idea is based on the following facts: (i) to transition from G1 to S phase and to commit to DNA synthesis, the cells must degrade the Cdk-2 inhibitors p27kip1 and p21 cip via the Skp1-Cullin-F-box protein/Skp2 (SCFSkp2) E3 ubiquitin ligase complex (Bornstein et al.,2003; Tsvetkov et al.,1999). This requires the Cdk-2-dependent phosphorylation of p27kip1 on Thr187 (Tsvetkov et al.,1999) and p21 cip1 on Ser130 (Bornstein et al.,2003); (ii) antiprogestins have a dual effect blocking Cdk-2 activity and triggering the accumulation of p21cip1 and p27kip1, and these Cdk-2 inhibitors rely on the UPS for their disappearance to enforce the orderly progression of the cell cycle from G1 to the S phase; (iii) there are remarkable similarities in the behavior of antiprogestins and proteasome inhibitors in inducing p21cip1 and p27kip1 accumulation before triggering caspase-associated lethality (Bazzaro et al.,2006; Freeburg et al.,2009a; Goyeneche et al.,2007). It is therefore possible that antiprogestins induce G1 growth arrest by interfering with the proteasome-mediated degradation of $\mathrm{p} 27 \mathrm{kip} 1 / \mathrm{p} 21$ cip1, leading to Cdk-2 inhibition. It is also reasonable that the sustained levels of p27kip and p21 cip1 in response to cytostatic doses of antiprogestins are the consequence of a reduced recognition of the Cdk inhibitors by the UPS. Because ovarian cancer cells function 
with high activity of the UPS (Bazzaro et al.,2006), this proteolytic machinery may be degrading Cdk inhibitors at a high rate, causing the reduced basal levels we found in ovarian cancer cells, thus favoring their proliferation. Antiprogestins may mitigate this process.

An additional potential mechanism mediating the anti-cell growth activity of antiprogestins is the induction of stress of the endoplasmic reticulum. A recent study showed that mifepristone induced an atypical unfolded protein response (UPR) in nonsmall lung cell carcinoma cells (Dioufa et al.,2010). The role of the endoplasmic reticulum responding to antiprogestins triggering the UPR, which could lead to either survival or death depending on the concentration of antiprogestins, is a provoking hypothesis that should be explored.

The newly discovered progesterone receptor membrane component 1 (PGRMC1) (Gellersen et al.,2009; Rohe et al.,2009) or the family of membrane PRs (mPR $\alpha, \beta, \gamma, \delta, \varepsilon)$ (Dressing et al.,2011; Gellersen et al.,2009; Thomas et al.,2007) may also mediate the antitumor effect of antiprogestins. For instance, PGRMC1 expression increases while cognate, nuclear progesterone receptor decreases in advanced stages of ovarian cancer, and overexpression of PGRMC1 interferes with the lethality of cisplatin, suggesting a survival role for PGRMC1 in ovarian cancer development (Peluso et al.,2008). In a panel of ovarian cancer cell lines expressing $\mathrm{mPR} \alpha, \mathrm{mPR} \beta$, and $\mathrm{mPR} \gamma$, but not cognate nuclear progesterone receptors, exposure to progesterone mediated the expression of proapoptotic proteins via activation of JNK and p38 MAPKs (Charles et al.,2010). Given that at micromolar concentrations the antiprogestin mifepristone operates as an agonist on both $\mathrm{mPR} \alpha$ and $\mathrm{mPR} \gamma$ when expressed in yeast (Smith et al.,2008), it is conceivable that antiprogestins carrying a similar structure (Fig.1) may mediate antiproliferation of cancer cells acting as agonists of mPRs.

\section{Strategy to utilize antiprogestins in ovarian cancer therapeutics}

\subsection{Blockage of ovarian cancer re-growth after platinum therapy}

We validated an in vitro model of ovarian cancer cell repopulation taking place among courses of lethal cisplatin therapy. Using this in vitro model system, we demonstrated that intertwining cytostatic concentrations of the antiprogestin mifepristone in between courses of cisplatin treatment is an efficacious strategy to prevent repopulation of ovarian cancer cells leading to a better treatment outcome; in addition, we found that chronic exposure to mifepristone after cisplatin enhances the killing efficacy of this cross-linking agent (Freeburg et al.,2009b). In this study, although the majority of the cells in the culture succumbed to the lethality of cisplatin, there were isolated cells that survived the treatment. These cells, because of their scarcity in the culture plate, may be easily missed in routine cell cultures if long-term follow-up is not conducted. When such a population of remnant cells that escaped the toxicity of platinum was exposed to cisplatin-free medium, the cells relapsed and repopulated the culture. We were able to document the relapse of highly sensitive OV2008 cells after three rounds of cisplatin treatment. The OV2008 cells repopulating after cisplatin incorporated more BrdUrd into their DNA when compared with exponentially growing, untreated cells, suggesting that an increased number of cells synthesizing DNA may be a product of accelerated cell repopulation (Kim\&Tannock,2005). When antiprogestin mifepristone was utilized chronically in between cisplatin treatment intervals, the cells that survived the treatment did not synthesize DNA, did not repopulate, and had a very poor 
clonogenic survival capacity, suggesting a permanent DNA damage to the cells not compatible with their survivability.

The nature of the cells that escape the lethality of cisplatin remains to be determined. There is a possibility that cisplatin is killing only the population of differentiated cancer cells representing the bulk of the culture, but not the scarce tumor initiating cells with the capacity to regenerate the culture, and that appear to be resistant to most common DNA damaging agents (Kvinlaug\&Huntly,2007). The presence of tumor initiating cells in ovarian cancer cell lines, however, has yet to be confirmed.

Alternatively, antiprogestins may block repopulation of cells after cisplatin by interfering with a cellular process termed reverse polyploidy or neosis (Erenpreisa\&Cragg,2007; Illidge et al.,2000; Sundaram et al.,2004). Cancer cells develop the capacity to escape DNA damage caused by pharmacological doses of platinum agents by reverse polyploidy, leading to the formation of diploid, rapid proliferating cells with increased platinum resistance (Puig et al.,2008). Thus, it is feasible that antiprogestins, when used chronically, block post-platinum repopulation by preventing reverse polyploidy. This hypothesis is based on the observation that OV2008 cells repopulating after cisplatin exposure show giant cells together with a nascent population of small cells (Freeburg et al.,2009b) that may originate from the likely polyploid, giant progenitors. Cultures treated with antiprogestins after platinum do not show this small pool of repopulating cells and instead display an overall reduced number of cells, with predominance of a giant phenotype that ends up committing suicide as marked by cleaved PARP positivity (Freeburg et al.,2009b).

\subsection{Potentiation of platinum induced lethality by antiprogestins}

We proved that intertwining cytostatic concentrations of antiprogestin mifepristone in between courses of lethal cisplatin-based chemotherapy not only resulted in an efficacious strategy to prevent repopulation of cancer cells in between lethal platinum treatment intervals, but it also potentiated the killing efficacy of cisplatin (Freeburg et al.,2009b).

When ovarian cancer cells are exposed to only mifepristone therapy, the cell cycle is arrested in the G1 phase (Goyeneche et al.,2007; Rose\&Barnea,1996). However, when antiprogestin mifepristone is added after cisplatin, the cells tend to accumulate at the $S$ and/or G2/M phases rather than in G1 (Gamarra-Luques\&Telleria,2010). This phenomenon may provide the rationale for the potentiation of platinum therapy by the antiprogestin. It is known that cisplatin treatment leads to a transitory S or G2 cell cycle arrest, which is utilized by the cells as an opportunity to repair any damaged DNA; however, if the DNA damage is significant and the DNA repair mechanisms cannot operate, the cells usually trigger their own demise (Sorenson et al.,1990). Thus, mifepristone may be a disruptor of the DNA damage and repair pathways operating after cisplatin exposure. Consequently the cells would enter an unscheduled mitosis with damaged DNA, which usually would trigger a cell death mechanism due to mitotic failure (Vakifahmetoglu et al.,2008). Partial support for this hypothesis is that cells receiving the combination treatment of cisplatin followed by mifepristone show an elevated percentage of cells allocated to the $M$ phase of the cell cycle suggested by 6 -fold overexpression of the mitotic marker, phospho-histone $\mathrm{H} 3$, when compared to cisplatinonly treated cultures (Freeburg et al.,2009b). This result, together with the data showing that the cultures receiving cisplatin followed by mifepristone express 4 -fold more cleaved PARP compared with cultures receiving only cisplatin (Freeburg et al.,2009b), indicate 
that cells chronically exposed to mifepristone after receiving lethal platinum therapy not only are unable to repopulate, but are also likely to die transiting into an unscheduled mitosis that could trigger cell death (i.e. mitotic death).

Mifepristone may be interfering with early steps in the DNA damage response pathway that lead to a failure of cells to arrest in the G2 phase when challenged with cisplatin. This rationale is supported by data generated utilizing the Chk-1 kinase inhibitor UCN-01 (7hydroxystaurosporine), which as a single agent is able to induce G1 growth arrest in nonsmall-cell lung carcinoma similar to the effect observed in ovarian cancer cells treated with mifepristone alone (Goyeneche et al.,2007). When UCN-01 was used after cisplatin, however, the combination was synergistic in terms of growth inhibition likely by reducing the time cells spend in the S or G2 phases to operate the DNA damage check point in order to allow repair the DNA damage induced by platinum (Mack et al.,2003).

We demonstrated that the cytostatic effect of mifepristone in ovarian cancer cells associates with an abrupt reduction in the activity of Cdk-2 (Goyeneche et al.,2007). In addition to its role in the cell cycle and cell survival previously stated, Cdk-2 has been implicated in DNA repair. For instance, the DNA repair machinery is dysfunctional in Cdk-2 deficient cells, and cells lacking the DNA repair component of BRCA1 are prone to cell death in response to Cdk-2 inhibition (Deans et al.,2006). This role played by Cdk-2 in the DNA repair process provides the rationale for a synergistic interaction of Cdk-2 inhibition and DNA damaging agents in the killing of cancer cells and could also explain the potentiation by mifepristone of platinum-induced lethality of ovarian cancer cells.

Another hypothesis as to how antiprogestin mifepristone can facilitate the lethal effect of cisplatin is based upon its capacity to abrogate the expression of the E2F1 transcription factor (Goyeneche et al.,2007). E2F1 is needed to regulate the expression of genes involved in the nucleotide excision DNA repair pathway (NER) (Berton et al.,2005), which is a major mechanism needed to repair $\sim 90 \%$ of the platinum-DNA intrastrand crosslinks (Cepeda et al.,2007; Helleday et al.,2008; Kelland,2007; Rabik\&Dolan,2007). Because in ovarian cancer increased expression of the endonuclease ERCC1 (excision repair cross-complementing-1) involved in NER has been correlated with cisplatin resistance (Li et al.,2000), and antisense RNA against ERCC1 sensitizes ovarian cancer cells to the lethality of cisplatin (Selvakumaran et al.,2003), it is possible that mifepristone potentiates cisplatin lethality by interfering with the functionality of the NER pathway. Antiprogestins may also dysregulate the homologous recombination DNA repair pathway responsible to repair the $\sim 10 \%$ DNA interstrand crosslinks induced by platinum agents; this avenue is of relevance as it is apparent that despite the majority of cisplatin binds DNA via intrastrand crosslinks, it is the low percentage of DNA interstrand crosslinks which causes most of its lethality (Wang\&Lippard,2005; Wang et al.,2011).

\section{Clinical relevance of repurposing antiprogestins for ovarian cancer treatment}

Based upon the evidence presented earlier in this chapter, antiprogestins - of which mifepristone and ulipristal are approved by the United States Food and Drug administration for reproductive medicine-can be re-purposed for another modality-of-use as part of the chemotherapeutic armamentarium for ovarian cancer patients. The translation of antiprogestin therapy to the clinic may have an impact in two manners: (i) adding an antiprogestin between rounds of platinum-based therapy should prevent the repopulation 
of ovarian cancer cells that escape the lethality of the platinum derivative, and improve treatment success in a synergistic manner when followed by antiprogestin maintenance therapy (compare models in Figs.3A vs.3B); and (ii) working as a single, cytostatic agent, a prototypical antiprogestin may be used for chronic maintenance therapy following lethal platinum agents to delay or avoid disease recurrence in a similar manner anti-estrogens are used to treat some cohorts of breast cancer patients (Osipo et al.,2004) (compare models in Figs.3A vs.3C).
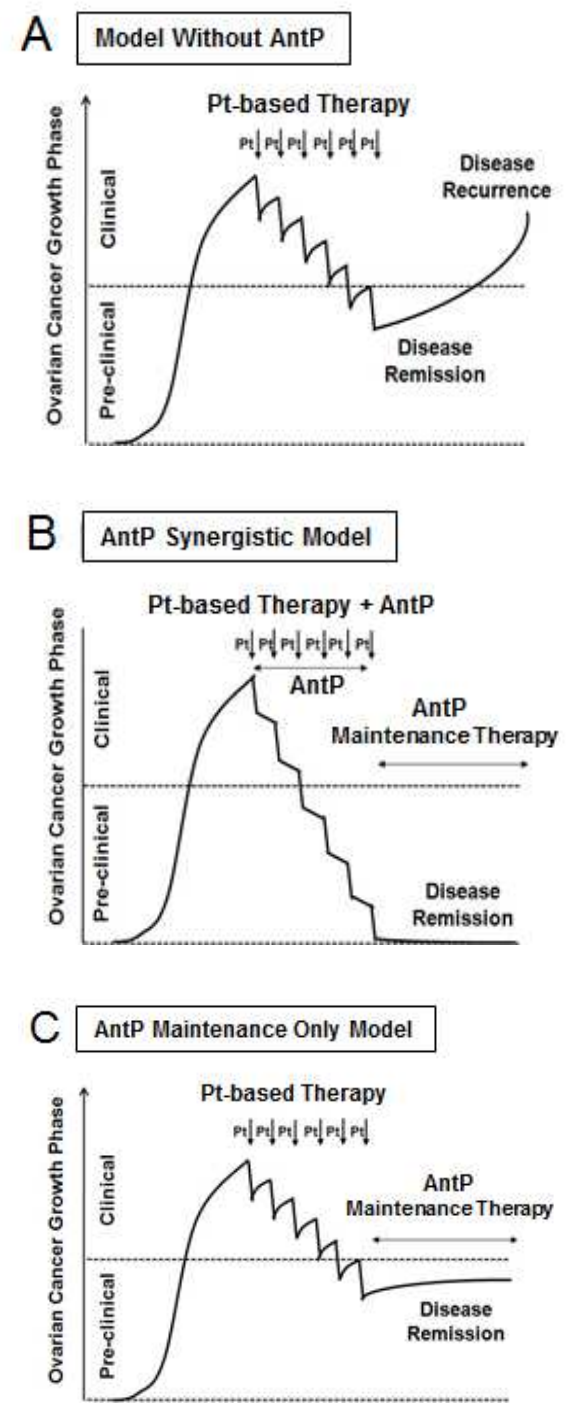

Fig. 3. Clinical translational impact of the use of antiprogestins (AntP) in the context of platinum $(\mathrm{Pt})$ based chemotherapy for ovarian cancer 


\section{Conclusions}

We have described a novel modality of action of antiprogestins acting as cytotoxic agents towards ovarian cancer, displaying a cytostatic effect at lower concentrations blocking cell growth at the G1 phase of the cell cycle, and a lethal effect at higher doses in association with morphological features of apoptosis and fragmentation of the genomic DNA. We have distinguished between lethal and cytostatic actions of these synthetic steroids, and provided evidence that Cdk-2 is involved as a downstream target of the anti-cancer effect of the drugs. Moreover, the remarkable increase in the number of dying cells when antiprogestin mifepristone followed cisplatin exposure (Freeburg et al.,2009b; GamarraLuques\&Telleria,2010) raises hope that adding antiprogestins to the platinum-based chemotherapeutic schedule in ovarian cancer should allow reducing either the number of platinum cycles or the dose of platinum without losing efficacy in terms of inhibition of tumor growth, yet reducing unwanted side effects. Consequently, the scheduling of antiprogestins between and/or after courses of platinum-based therapy for human ovarian cancer has reasonable potential for improving treatment success, extending the quality and quality of life of patients suffering from this disease.

We have provided data supporting the feasibility for re-repurposing or re-repositioning of antiprogestins originally designed to operate as antiglucocorticoid or antiprogestins, to chronically treat ovarian cancer patients, as it is currently done with antiestrogen therapy for breast cancer. In particular, the emergent role of ORG-31710 and CDB-2914 having far less antiglucocorticoid effects than mifepristone but maintaining its anti-ovarian cancer properties is promising for translation to the clinic.

\section{Acknowledgement}

This research was supported by award number K22CA121991 and ARRA Supplement K22CA121991-S1 from the National Cancer Institute, the National Institutes of Health (NIH). The authors would like to thank Mr. Nahuel Telleria for editing the manuscript.

\section{References}

Akahira, J., Suzuki, T., Ito, K., Kaneko, C., Darnel, A. D., Moriya, T., Okamura, K., Yaegashi, N.\&Sasano, H. (2002). Differential expression of progesterone receptor isoforms A and $\mathrm{B}$ in the normal ovary, and in benign, borderline, and malignant ovarian tumors. Jpn J Cancer Res 93(7): 807-815.

Arimoto-Ishida, E., Ohmichi, M., Mabuchi, S., Takahashi, T., Ohshima, C., Hayakawa, J., Kimura, A., Takahashi, K., Nishio, Y., Sakata, M., Kurachi, H., Tasaka, K.\&Murata, Y. (2004). Inhibition of phosphorylation of a forkhead transcription factor sensitizes human ovarian cancer cells to cisplatin. Endocrinology 145(4): 2014-2022.

Baulieu, E. E. (1991). The antisteroid RU486: its cellular and molecular mode of action. Trends Endocrinol Metab 2(6): 233-239.

Bazzaro, M., Lee, M. K., Zoso, A., Stirling, W. L., Santillan, A., Shih Ie, M.\&Roden, R. B. (2006). Ubiquitin-proteasome system stress sensitizes ovarian cancer to proteasome inhibitor-induced apoptosis. Cancer Res 66(7): 3754-3763. 
Belanger, A., Philibert, D.\&Teutsch, G. (1981). Regio and stereospecific synthesis of 11 betasubstituted 19-norsteroids. Influence of 11 beta-substitution on progesterone receptor affinity - (1). Steroids 37(4): 361-382.

Benagiano, G., Bastianelli, C.\&Farris, M. (2008a). Selective progesterone receptor modulators 1: use during pregnancy. Expert Opin Pharmacother 9(14): 2459-2472.

Benagiano, G., Bastianelli, C.\&Farris, M. (2008b). Selective progesterone receptor modulators 2: use in reproductive medicine. Expert Opin Pharmacother 9(14): 2473-2485.

Benagiano, G., Bastianelli, C.\&Farris, M. (2008c). Selective progesterone receptor modulators 3: use in oncology, endocrinology and psychiatry. Expert Opin Pharmacother 9(14): 2487-2496.

Berton, T. R., Mitchell, D. L., Guo, R.\&Johnson, D. G. (2005). Regulation of epidermal apoptosis and DNA repair by E2F1 in response to ultraviolet B radiation. Oncogene 24(15): 2449-2460.

Bornstein, G., Bloom, J., Sitry-Shevah, D., Nakayama, K., Pagano, M.\&Hershko, A. (2003). Role of the SCFSkp2 ubiquitin ligase in the degradation of p21Cip1 in S phase. J Biol Chem 278(28): 25752-25757.

Brown, K. A., Roberts, R. L., Arteaga, C. L.\&Law, B. K. (2004). Transforming growth factorbeta induces Cdk2 relocalization to the cytoplasm coincident with dephosphorylation of retinoblastoma tumor suppressor protein. Breast Cancer Res 6(2): R130-139.

Bukowski, R. M., Ozols, R. F.\&Markman, M. (2007). The management of recurrent ovarian cancer. Semin Oncol 34(2 Suppl 2): S1-15.

Cannistra, S. A. (2004). Cancer of the ovary. N Engl J Med 351(24): 2519-2529.

Casalini, P., Botta, L.\&Menard, S. (2001). Role of p53 in HER2-induced proliferation or apoptosis. J Biol Chem 276(15): 12449-12453.

Cepeda, V., Fuertes, M. A., Castilla, J., Alonso, C., Quevedo, C.\&Perez, J. M. (2007). Biochemical mechanisms of cisplatin cytotoxicity. Anticancer Agents Med Chem 7(1): 3-18.

Charles, N. J., Thomas, P.\&Lange, C. A. (2010). Expression of membrane progesterone receptors (mPR/PAQR) in ovarian cancer cells: implications for progesteroneinduced signaling events. Horm Canc 1(4): 167-176.

Check, J. H., Dix, E., Cohen, R., Check, D.\&Wilson, C. (2010a). Efficacy of the progesterone receptor antagonist mifepristone for palliative therapy of patients with a variety of advanced cancer types. Anticancer Res 30(2): 623-628.

Check, J. H., Sansoucie, L., Chern, J., Amadi, N.\&Katz, Y. (2009). Mifepristone treatment improves length and quality of survival of mice with spontaneous leukemia. Anticancer Res 29(8): 2977-2980.

Check, J. H., Sansoucie, L., Chern, J.\&Dix, E. (2010b). Mifepristone treatment improves length and quality of survival of mice with spontaneous lung cancer. Anticancer Res 30(1): 119-122.

Conradie, R., Bruggeman, F. J., Ciliberto, A., Csikasz-Nagy, A., Novak, B., Westerhoff, H. V.\&Snoep, J. L. (2010). Restriction point control of the mammalian cell cycle via the cyclin E/Cdk2:p27 complex. FEBS J 277(2): 357-367.

Deans, A. J., Khanna, K. K., McNees, C. J., Mercurio, C., Heierhorst, J.\&McArthur, G. A. (2006). Cyclin-dependent kinase 2 functions in normal DNA repair and is a therapeutic target in BRCA1-deficient cancers. Cancer Res 66(16): 8219-8226. 
Despierre, E., Lambrechts, D., Neven, P., Amant, F., Lambrechts, S.\&Vergote, I. (2010). The molecular genetic basis of ovarian cancer and its roadmap towards a better treatment. Gynecol Oncol 117(2): 358-365.

Dioufa, N., Kassi, E., Papavassiliou, A. G.\&Kiaris, H. (2010). Atypical induction of the unfolded protein response by mifepristone. Endocrine 38(2): 167-173.

DiSaia, P. J.\&Bloss, J. D. (2003). Treatment of ovarian cancer: new strategies. Gynecol Oncol 90(2 Pt 2): S24-32.

Dressing, G. E., Goldberg, J. E., Charles, N. J., Schwertfeger, K. L.\&Lange, C. A. (2011). Membrane progesterone receptor expression in mammalian tissues: A review of regulation and physiological implications. Steroids 76(1-2): 11-17.

Eisinger, S. H., Fiscella, J., Bonfiglio, T., Meldrum, S.\&Fiscella, K. (2009). Open-label study of ultra low-dose mifepristone for the treatment of uterine leiomyomata. Eur J Obstet Gynecol Reprod Biol 146(2): 215-218.

El Etreby, M. F., Liang, Y., Johnson, M. H.\&Lewis, R. W. (2000a). Antitumor activity of mifepristone in the human $\mathrm{LNCaP}, \mathrm{LNCaP}-\mathrm{C} 4$, and $\mathrm{LNCaP}-\mathrm{C} 4-2$ prostate cancer models in nude mice. Prostate 42(2): 99-106.

El Etreby, M. F., Liang, Y.\&Lewis, R. W. (2000b). Induction of apoptosis by mifepristone and tamoxifen in human LNCaP prostate cancer cells in culture. Prostate 43(1): 31-42.

El Etreby, M. F., Liang, Y., Wrenn, R. W.\&Schoenlein, P. V. (1998). Additive effect of mifepristone and tamoxifen on apoptotic pathways in MCF-7 human breast cancer cells. Breast Cancer Res Treat 51(2): 149-168.

Erenpreisa, J.\&Cragg, M. S. (2007). Cancer: a matter of life cycle? Cell Biol Int 31(12): 15071510.

Fedele, L.\&Berlanda, N. (2004). Emerging drugs for endometriosis. Expert Opin Emerg Drugs 9(1): 167-177.

Fjelldal, R., Moe, B. T., Orbo, A.\&Sager, G. (2010). MCF-7 cell apoptosis and cell cycle arrest: non-genomic effects of progesterone and mifepristone (RU-486). Anticancer Res 30(12): 4835-4840.

Flores, O., Wang, Z., Knudsen, K. E.\&Burnstein, K. L. (2010). Nuclear targeting of cyclindependent kinase 2 reveals essential roles of cyclin-dependent kinase 2 localization and cyclin E in vitamin D-mediated growth inhibition. Endocrinology 151(3): 896908.

Fraser, M., Leung, B. M., Yan, X., Dan, H. C., Cheng, J. Q.\&Tsang, B. K. (2003). p53 is a determinant of X-linked inhibitor of apoptosis protein/Akt-mediated chemoresistance in human ovarian cancer cells. Cancer Res 63(21): 7081-7088.

Freeburg, E. M., Goyeneche, A. A., Seidel, E. E.\&Telleria, C. M. (2009a). Resistance to cisplatin does not affect sensitivity of human ovarian cancer cell lines to mifepristone cytotoxicity. Cancer Cell Int 9: 4.

Freeburg, E. M., Goyeneche, A. A.\&Telleria, C. M. (2009b). Mifepristone abrogates repopulation of ovarian cancer cells in between courses of cisplatin treatment. Int J Oncol 34(3): 743-755.

Gaddy, V. T., Barrett, J. T., Delk, J. N., Kallab, A. M., Porter, A. G.\&Schoenlein, P. V. (2004). Mifepristone induces growth arrest, caspase activation, and apoptosis of estrogen receptor-expressing, antiestrogen-resistant breast cancer cells. Clin Cancer Res 10(15): 5215-5225. 
Gamarra-Luques, C. D.\&Telleria, C. M. (2010). Enhancement of the lethality of platinumbased therapy by antiprogestin mifepristone in ovarian cancer. Cancer Epidemiology Biomarkers \& Prevention 19(10): Supplement 1, A113

Gellersen, B., Fernandes, M. S.\&Brosens, J. J. (2009). Non-genomic progesterone actions in female reproduction. Hum Reprod Update 15(1): 119-138.

Gordon, A. N., Tonda, M., Sun, S.\&Rackoff, W. (2004). Long-term survival advantage for women treated with pegylated liposomal doxorubicin compared with topotecan in a phase 3 randomized study of recurrent and refractory epithelial ovarian cancer. Gynecol Oncol 95(1): 1-8.

Goyeneche, A. A., Caron, R. W.\&Telleria, C. M. (2007). Mifepristone inhibits ovarian cancer cell growth in vitro and in vivo. Clin Cancer Res 13(11): 3370-3379.

Goyeneche, A. A., Seidel, E. E.\&Telleria, C. M. (2011). Growth inhibition induced by antiprogestins RU-38486, ORG-31710, and CDB-2914 in ovarian cancer cells involves inhibition of cyclin dependent kinase 2. Invest New Drugs [Published ahead of print].

Grunberg, S. M., Weiss, M. H., Russell, C. A., Spitz, I. M., Ahmadi, J., Sadun, A.\&SitrukWare, R. (2006). Long-term administration of mifepristone (RU486): clinical tolerance during extended treatment of meningioma. Cancer Invest 24(8): 727-733.

Grunberg, S. M., Weiss, M. H., Spitz, I. M., Ahmadi, J., Sadun, A., Russell, C. A., Lucci, L.\&Stevenson, L. L. (1991). Treatment of unresectable meningiomas with the antiprogesterone agent mifepristone. J Neurosurg 74(6): 861-866.

Hamilton, T. C., Behrens, B. C., Louie, K. G.\&Ozols, R. F. (1984). Induction of progesterone receptor with 17 beta-estradiol in human ovarian cancer. J Clin Endocrinol Metab 59(3): 561-563.

Han, S.\&Sidell, N. (2003). RU486-induced growth inhibition of human endometrial cells involves the nuclear factor-kappa B signaling pathway. J Clin Endocrinol Metab 88(2): 713-719.

Havrilesky, L., Darcy, M., Hamdan, H., Priore, R. L., Leon, J., Bell, J.\&Berchuck, A. (2003). Prognostic significance of p53 mutation and p53 overexpression in advanced epithelial ovarian cancer: a Gynecologic Oncology Group Study. J Clin Oncol 21(20): 3814-3825.

Hayakawa, J., Ohmichi, M., Kurachi, H., Ikegami, H., Kimura, A., Matsuoka, T., Jikihara, H., Mercola, D.\&Murata, Y. (1999). Inhibition of extracellular signal-regulated protein kinase or c-Jun N-terminal protein kinase cascade, differentially activated by cisplatin, sensitizes human ovarian cancer cell line. J Biol Chem 274(44): 3164831654 .

Helleday, T., Petermann, E., Lundin, C., Hodgson, B.\&Sharma, R. A. (2008). DNA repair pathways as targets for cancer therapy. Nat Rev Cancer 8(3): 193-204.

Herzog, T. J. (2006). The current treatment of recurrent ovarian cancer. Curr Oncol Rep 8(6): 448-454.

Ho, P. C., Yu Ng, E. H.\&Tang, O. S. (2002). Mifepristone: contraceptive and noncontraceptive uses. Curr Opin Obstet Gynecol 14(3): 325-330.

Huang, H., Regan, K. M., Lou, Z., Chen, J.\&Tindall, D. J. (2006). CDK2-dependent phosphorylation of FOXO1 as an apoptotic response to DNA damage. Science 314(5797): 294-297. 
Huang, H.\&Tindall, D. J. (2007). CDK2 and FOXO1: a fork in the road for cell fate decisions. Cell Cycle 6(8): 902-906.

Illidge, T. M., Cragg, M. S., Fringes, B., Olive, P.\&Erenpreisa, J. A. (2000). Polyploid giant cells provide a survival mechanism for p53 mutant cells after DNA damage. Cell Biol Int 24(9): 621-633.

Jemal, A., Siegel, R., Ward, E., Murray, T., Xu, J., Smigal, C.\&Thun, M. J. (2006). Cancer statistics, 2006. CA Cancer J Clin 56(2): 106-130.

Jurado, R., Lopez-Flores, A., Alvarez, A.\&Garcia-Lopez, P. (2009). Cisplatin cytotoxicity is increased by mifepristone in cervical carcinoma: an in vitro and in vivo study. Oncol Rep 22(5): 1237-1245.

Kahmann, S., Vassen, L.\&Klein-Hitpass, L. (1998). Synergistic enhancement of PRBmediated RU486 and R5020 agonist activities through cyclic adenosine 3', 5'monophosphate represents a delayed primary response. Mol Endocrinol 12(2): 278289.

Katano, K., Kondo, A., Safaei, R., Holzer, A., Samimi, G., Mishima, M., Kuo, Y. M., Rochdi, M.\&Howell, S. B. (2002). Acquisition of resistance to cisplatin is accompanied by changes in the cellular pharmacology of copper. Cancer Res 62(22): 6559-6565.

Keith Bechtel, M.\&Bonavida, B. (2001). Inhibitory effects of 17beta-estradiol and progesterone on ovarian carcinoma cell proliferation: a potential role for inducible nitric oxide synthase. Gynecol Oncol 82(1): 127-138.

Kelland, L. (2007). The resurgence of platinum-based cancer chemotherapy. Nat Rev Cancer 7(8): 573-584.

Kettel, L. M., Murphy, A. A., Morales, A. J.\&Yen, S. S. (1994). Clinical efficacy of the antiprogesterone RU486 in the treatment of endometriosis and uterine fibroids. Hum Reprod 9 Suppl 1: 116-120.

Kim, J. J.\&Tannock, I. F. (2005). Repopulation of cancer cells during therapy: an important cause of treatment failure. Nat Rev Cancer 5(7): 516-525.

Kino, T., Manoli, I., Kelkar, S., Wang, Y., Su, Y. A.\&Chrousos, G. P. (2009). Glucocorticoid receptor (GR) beta has intrinsic, GRalpha-independent transcriptional activity. Biochem Biophys Res Commun 381(4): 671-675.

Kloosterboer, H. J., Deckers, G. H., Schoonen, W. G., Hanssen, R. G., Rose, U. M., Verbost, P. M., Hsiu, J. G., Williams, R. F.\&Hodgen, G. D. (2000). Preclinical experience with two selective progesterone receptor modulators on breast and endometrium. Steroids 65(10-11): 733-740.

Kvinlaug, B. T.\&Huntly, B. J. (2007). Targeting cancer stem cells. Expert Opin Ther Targets 11(7): 915-927.

Lents, N. H., Keenan, S. M., Bellone, C.\&Baldassare, J. J. (2002). Stimulation of the Raf/MEK/ERK cascade is necessary and sufficient for activation and Thr-160 phosphorylation of a nuclear-targeted CDK2. J Biol Chem 277(49): 47469-47475.

Levens, E. D., Potlog-Nahari, C., Armstrong, A. Y., Wesley, R., Premkumar, A., Blithe, D. L., Blocker, W.\&Nieman, L. K. (2008). CDB-2914 for uterine leiomyomata treatment: a randomized controlled trial. Obstet Gynecol 111(5): 1129-1136.

Lewis-Tuffin, L. J., Jewell, C. M., Bienstock, R. J., Collins, J. B.\&Cidlowski, J. A. (2007). Human glucocorticoid receptor beta binds RU-486 and is transcriptionally active. Mol Cell Biol 27(6): 2266-2282. 
Li, D.-Q., Wang, Z.-B., Bai, J., Zhao, J., Wang, Y., Hu, K.\&Du, Y.-H. (2004). Effects of mifepristone on proliferation of human gastric adenocarcinoma cell line SGC-7901 in vitro. World Journal of Gastroenterology 10(18): 2628-2631.

Li, Q., Yu, J. J., Mu, C., Yunmbam, M. K., Slavsky, D., Cross, C. L., Bostick-Bruton, F.\&Reed, E. (2000). Association between the level of ERCC-1 expression and the repair of cisplatin-induced DNA damage in human ovarian cancer cells. Anticancer Res 20(2A): 645-652.

Liang, Y., Eid, M. A., El Etreby, F., Lewis, R. W.\&Kumar, M. V. (2002). Mifepristone-induced secretion of transforming growth factor beta1-induced apoptosis in prostate cancer cells. Int J Oncol 21(6): 1259-1267.

Liang, Y., Hou, M., Kallab, A. M., Barrett, J. T., El Etreby, F.\&Schoenlein, P. V. (2003). Induction of antiproliferation and apoptosis in estrogen receptor negative MDA231 human breast cancer cells by mifepristone and 4-hydroxytamoxifen combination therapy: a role for TGFbeta1. Int J Oncol 23(2): 369-380.

Liberto, M.\&Cobrinik, D. (2000). Growth factor-dependent induction of p21(CIP1) by the green tea polyphenol, epigallocatechin gallate. Cancer Lett 154(2): 151-161.

Liu, M., Wikonkal, N. M.\&Brash, D. E. (1999). Induction of cyclin-dependent kinase inhibitors and $\mathrm{G}(1)$ prolongation by the chemopreventive agent $\mathrm{N}$-acetylcysteine. Carcinogenesis 20(9): 1869-1872.

Liu, Y., Wang, L. L.\&Deng, Y. (2003). Enhancement of antitumor effect of cisplatin against human ovarian carcinoma cells by mifepristone in vivo. Di Yi Jun Yi Da Xue Xue Bao 23(3): 242-244.

Lu, X., Errington, J., Curtin, N. J., Lunec, J.\&Newell, D. R. (2001). The impact of p53 status on cellular sensitivity to antifolate drugs. Clin Cancer Res 7(7): 2114-2123.

Mack, P. C., Gandara, D. R., Lau, A. H., Lara, P. N., Jr., Edelman, M. J.\&Gumerlock, P. H. (2003). Cell cycle-dependent potentiation of cisplatin by UCN-01 in non-small-cell lung carcinoma. Cancer Chemother Pharmacol 51(4): 337-348.

Mao, J., Regelson, W.\&Kalimi, M. (1992). Molecular mechanism of RU 486 action: a review. Mol Cell Biochem 109(1): 1-8.

Martin, V. R. (2007). Ovarian cancer: an overview of treatment options. Clin J Oncol Nurs 11(2): 201-207.

Matsuda, Y., Kawamoto, K., Kiya, K., Kurisu, K., Sugiyama, K.\&Uozumi, T. (1994). Antitumor effects of antiprogesterones on human meningioma cells in vitro and in vivo. J Neurosurg 80(3): 527-534.

McDonnel, A. C.\&Murdoch, W. J. (2001). High-dose progesterone inhibition of urokinase secretion and invasive activity by SKOV-3 ovarian carcinoma cells: evidence for a receptor-independent nongenomic effect on the plasma membrane. I Steroid Biochem Mol Biol 78(2): 185-191.

Modesitt, S. C.\&Jazaeri, A. A. (2007). Recurrent epithelial ovarian cancer: pharmacotherapy and novel therapeutics. Expert Opin Pharmacother 8(14): 2293-2305.

Moe, B. G., Vereide, A. B., Orbo, A.\&Sager, G. (2009). High concentrations of progesterone and mifepristone mutually reinforce cell cycle retardation and induction of apoptosis. Anticancer Res 29(4): 1053-1058.

Moller, C., Hoffmann, J., Kirkland, T. A.\&Schwede, W. (2008). Investigational developments for the treatment of progesterone-dependent diseases. Expert Opin Investig Drugs 17(4): 469-479. 
Mukherjee, K., Syed, V.\&Ho, S. M. (2005). Estrogen-induced loss of progesterone receptor expression in normal and malignant ovarian surface epithelial cells. Oncogene 24(27): 4388-4400.

Murphy, A. A., Morales, A. J., Kettel, L. M.\&Yen, S. S. (1995). Regression of uterine leiomyomata to the antiprogesterone RU486: dose-response effect. Fertil Steril 64(1): 187-190.

Murphy, A. A., Zhou, M. H., Malkapuram, S., Santanam, N., Parthasarathy, S.\&Sidell, N. (2000). RU486-induced growth inhibition of human endometrial cells. Fertil Steril 74(5): 1014-1019.

Musgrove, E. A., Lee, C. S., Cornish, A. L., Swarbrick, A.\&Sutherland, R. L. (1997). Antiprogestin inhibition of cell cycle progression in T-47D breast cancer cells is accompanied by induction of the cyclin-dependent kinase inhibitor p21. Mol Endocrinol 11(1): 54-66.

Naora, H.\&Montell, D. J. (2005). Ovarian cancer metastasis: integrating insights from disparate model organisms. Nat Rev Cancer 5(5): 355-366.

Narvekar, N., Cameron, S., Critchley, H. O., Lin, S., Cheng, L.\&Baird, D. T. (2004). Low-dose mifepristone inhibits endometrial proliferation and up-regulates androgen receptor. J Clin Endocrinol Metab 89(5): 2491-2497.

O'Connor, P. M., Jackman, J., Bae, I., Myers, T. G., Fan, S., Mutoh, M., Scudiero, D. A., Monks, A., Sausville, E. A., Weinstein, J. N., Friend, S., Fornace, A. J., Jr.\&Kohn, K. W. (1997). Characterization of the p53 tumor suppressor pathway in cell lines of the National Cancer Institute anticancer drug screen and correlations with the growthinhibitory potency of 123 anticancer agents. Cancer Res 57(19): 4285-4300.

Oakley, R. H., Jewell, C. M., Yudt, M. R., Bofetiado, D. M.\&Cidlowski, J. A. (1999). The dominant negative activity of the human glucocorticoid receptor beta isoform. Specificity and mechanisms of action. J Biol Chem 274(39): 27857-27866.

Ormerod, M. G., O'Neill, C., Robertson, D., Kelland, L. R.\&Harrap, K. R. (1996). cisDiamminedichloroplatinum(II)-induced cell death through apoptosis in sensitive and resistant human ovarian carcinoma cell lines. Cancer Chemother Pharmacol 37(5): 463-471.

Osipo, C., Liu, H., Meeke, K.\&Jordan, V. C. (2004). The consequences of exhaustive antiestrogen therapy in breast cancer: estrogen-induced tumor cell death. Exp Biol Med (Maywood) 229(8): 722-731.

Ozols, R. F. (2006a). Challenges for chemotherapy in ovarian cancer. Ann Oncol 17 Suppl 5: v181-187.

Ozols, R. F. (2006b). Systemic therapy for ovarian cancer: current status and new treatments. Semin Oncol 33(2 Suppl 6): S3-11.

Parthasarathy, S., Morales, A. J.\&Murphy, A. A. (1994). Antioxidant: a new role for RU-486 and related compounds. J Clin Invest 94(5): 1990-1995.

Pectasides, D., Psyrri, A., Pectasides, M.\&Economopoulos, T. (2006). Optimal therapy for platinum-resistant recurrent ovarian cancer: doxorubicin, gemcitabine or topotecan? Expert Opin Pharmacother 7(8): 975-987.

Peluso, J. J., Liu, X., Saunders, M. M., Claffey, K. P.\&Phoenix, K. (2008). Regulation of ovarian cancer cell viability and sensitivity to cisplatin by progesterone receptor membrane component-1. J Clin Endocrinol Metab 93(5): 1592-1599. 
Philibert, D., Moguilewsky, M., Mary, I., Lecaque, D., Tournemine, C., Secchi, J.\&Deraedt, R. (1985). Pharmacological profile of RU486 in animals. The Antiprogesterone Steroid RU486 and Human Fertility Control. E. E. Baulieu and S. J. Segal. NY, Plenum Press.

Poole, A. J., Li, Y., Kim, Y., Lin, S. C., Lee, W. H.\&Lee, E. Y. (2006). Prevention of Brca1mediated mammary tumorigenesis in mice by a progesterone antagonist. Science 314(5804): 1467-1470.

Puig, P. E., Guilly, M. N., Bouchot, A., Droin, N., Cathelin, D., Bouyer, F., Favier, L., Ghiringhelli, F., Kroemer, G., Solary, E., Martin, F.\&Chauffert, B. (2008). Tumor cells can escape DNA-damaging cisplatin through DNA endoreduplication and reversible polyploidy. Cell Biol Int 32(9): 1031-1043.

Qin, T. N.\&Wang, L. L. (2002). Enhanced sensitivity of ovarian cell line to cisplatin induced by mifepristone and its mechanism. Di Yi Jun Yi Da Xue Xue Bao 22(4): 344-346.

Rabik, C. A.\&Dolan, M. E. (2007). Molecular mechanisms of resistance and toxicity associated with platinating agents. Cancer Treat Rev 33(1): 9-23.

Reid, T., Jin, X., Song, H., Tang, H. J., Reynolds, R. K.\&Lin, J. (2004). Modulation of Janus kinase 2 by p53 in ovarian cancer cells. Biochem Biophys Res Commun 321(2): 441-447.

Roberts, C. P., Parthasarathy, S., Gulati, R., Horowitz, I.\&Murphy, A. A. (1995). Effect of RU486 and related compounds on the proliferation of cultured macrophages. Am J Reprod Immunol 34(4): 248-256.

Rocereto, T. F., Saul, H. M., Aikins, J. A., Jr.\&Paulson, J. (2000). Phase II study of mifepristone (RU486) in refractory ovarian cancer. Gynecol Oncol 77(3): 429-432.

Rohe, H. J., Ahmed, I. S., Twist, K. E.\&Craven, R. J. (2009). PGRMC1 (progesterone receptor membrane component 1): a targetable protein with multiple functions in steroid signaling, P450 activation and drug binding. Pharmacol Ther 121(1): 14-19.

Rose, F. V.\&Barnea, E. R. (1996). Response of human ovarian carcinoma cell lines to antiprogestin mifepristone. Oncogene 12(5): 999-1003.

Rosen, D. G., Yang, G., Cai, K. Q., Bast, R. C., Jr., Gershenson, D. M., Silva, E. G.\&Liu, J. (2005). Subcellular localization of p27kip1 expression predicts poor prognosis in human ovarian cancer. Clin Cancer Res 11(2 Pt 1): 632-637.

Sartorius, C. A., Tung, L., Takimoto, G. S.\&Horwitz, K. B. (1993). Antagonist-occupied human progesterone receptors bound to DNA are functionally switched to transcriptional agonists by cAMP. J Biol Chem 268(13): 9262-9266.

Sasaki, H., Sheng, Y., Kotsuji, F.\&Tsang, B. K. (2000). Down-regulation of X-linked inhibitor of apoptosis protein induces apoptosis in chemoresistant human ovarian cancer cells. Cancer Res 60(20): 5659-5666.

Schneider, C. C., Gibb, R. K., Taylor, D. D., Wan, T.\&Gercel-Taylor, C. (1998). Inhibition of endometrial cancer cell lines by mifepristone (RU 486). J Soc Gynecol Investig 5(6): 334-338.

Schoenlein, P. V., Hou, M., Samaddar, J. S., Gaddy, V. T., Thangaraju, M., Lewis, J., Johnson, M., Ganapathy, V., Kallab, A.\&Barrett, J. T. (2007). Downregulation of retinoblastoma protein is involved in the enhanced cytotoxicity of 4hydroxytamoxifen plus mifepristone combination therapy versus antiestrogen monotherapy of human breast cancer. Int J Oncol 31(3): 643-655.

Scovassi, A. I.\&Poirier, G. G. (1999). Poly(ADP-ribosylation) and apoptosis. Mol Cell Biochem 199(1-2): 125-137. 
Selvakumaran, M., Pisarcik, D. A., Bao, R., Yeung, A. T.\&Hamilton, T. C. (2003). Enhanced cisplatin cytotoxicity by disturbing the nucleotide excision repair pathway in ovarian cancer cell lines. Cancer Res 63(6): 1311-1316.

Shaw, T. J., Senterman, M. K., Dawson, K., Crane, C. A.\&Vanderhyden, B. C. (2004). Characterization of intraperitoneal, orthotopic, and metastatic xenograft models of human ovarian cancer. Mol Ther 10(6): 1032-1042.

Siddik, Z. H., Mims, B., Lozano, G.\&Thai, G. (1998). Independent pathways of p53 induction by cisplatin and X-rays in a cisplatin-resistant ovarian tumor cell line. Cancer Res 58(4): 698-703.

Smith, J. L., Kupchak, B. R., Garitaonandia, I., Hoang, L. K., Maina, A. S., Regalla, L. M.\&Lyons, T. J. (2008). Heterologous expression of human mPRalpha, mPRbeta and mPRgamma in yeast confirms their ability to function as membrane progesterone receptors. Steroids 73(11): 1160-1173.

Sorenson, C. M., Barry, M. A.\&Eastman, A. (1990). Analysis of events associated with cell cycle arrest at G2 phase and cell death induced by cisplatin. J Natl Cancer Inst 82(9): 749-755.

Spitz, I. M. (2006). Progesterone receptor antagonists. Curr Opin Investig Drugs 7(10): 882890.

Steinauer, J., Pritts, E. A., Jackson, R.\&Jacoby, A. F. (2004). Systematic review of mifepristone for the treatment of uterine leiomyomata. Obstet Gynecol 103(6): 1331-1336.

Sui, L., Dong, Y., Ohno, M., Sugimoto, K., Tai, Y., Hando, T.\&Tokuda, M. (2001). Implication of malignancy and prognosis of p27(kip1), Cyclin E, and Cdk2 expression in epithelial ovarian tumors. Gynecol Oncol 83(1): 56-63.

Sundaram, M., Guernsey, D. L., Rajaraman, M. M.\&Rajaraman, R. (2004). Neosis: a novel type of cell division in cancer. Cancer Biol Ther 3(2): 207-218.

Svensson, E. C., Markstrom, E., Shao, R., Andersson, M.\&Billig, H. (2001). Progesterone receptor antagonists Org 31710 and RU 486 increase apoptosis in human periovulatory granulosa cells. Fertil Steril 76(6): 1225-1231.

Syed, V.\&Ho, S. M. (2003). Progesterone-induced apoptosis in immortalized normal and malignant human ovarian surface epithelial cells involves enhanced expression of FasL. Oncogene 22(44): 6883-6890.

Syed, V., Mukherjee, K., Godoy-Tundidor, S.\&Ho, S. M. (2007). Progesterone induces apoptosis in TRAIL-resistant ovarian cancer cells by circumventing c-FLIPL overexpression. J Cell Biochem 102(2): 442-452.

Syed, V., Ulinski, G., Mok, S. C., Yiu, G. K.\&Ho, S. M. (2001). Expression of gonadotropin receptor and growth responses to key reproductive hormones in normal and malignant human ovarian surface epithelial cells. Cancer Res 61(18): 6768-6776.

Taniguchi, Y., Iwasaki, Y., Tsugita, M., Nishiyama, M., Taguchi, T., Okazaki, M., Nakayama, S., Kambayashi, M., Hashimoto, K.\&Terada, Y. (2010). Glucocorticoid receptor-beta and receptor-gamma exert dominant negative effect on gene repression but not on gene induction. Endocrinology 151(7): 3204-3213.

Thomas, P., Pang, Y., Dong, J., Groenen, P., Kelder, J., de Vlieg, J., Zhu, Y.\&Tubbs, C. (2007). Steroid and $\mathrm{G}$ protein binding characteristics of the seatrout and human progestin membrane receptor alpha subtypes and their evolutionary origins. Endocrinology 148(2): 705-718. 
Tieszen, C. R., Goyeneche, A. A., Brandhagen, B. N., Ortbahn, C. T.\&Telleria, C. M. (2011). Antiprogestin mifepristone inhibits the growth of cancer cells of reproductive and non-reproductive origin regardless of progesterone receptor expression. BMC Cancer 11(1): 207.

Tsvetkov, L. M., Yeh, K. H., Lee, S. J., Sun, H.\&Zhang, H. (1999). p27(Kip1) ubiquitination and degradation is regulated by the $\mathrm{SCF}(\mathrm{Skp} 2)$ complex through phosphorylated Thr187 in p27. Curr Biol 9(12): 661-664.

Vakifahmetoglu, H., Olsson, M.\&Zhivotovsky, B. (2008). Death through a tragedy: mitotic catastrophe. Cell Death Differ 15(7): 1153-1162.

Vasey, P. A. (2003). Resistance to chemotherapy in advanced ovarian cancer: mechanisms and current strategies. Br J Cancer 89 Suppl 3: S23-28.

Wang, D.\&Lippard, S. J. (2005). Cellular processing of platinum anticancer drugs. Nat Rev Drug Discov 4(4): 307-320.

Wang, Q. E., Milum, K., Han, C., Huang, Y. W., Wani, G., Thomale, J.\&Wani, A. A. (2011). Differential contributory roles of nucleotide excision and homologous recombination repair for enhancing cisplatin sensitivity in human ovarian cancer cells. Mol Cancer 10: 24.

Wiehle, R. D., Christov, K.\&Mehta, R. (2007). Anti-progestins suppress the growth of established tumors induced by 7, 12-dimethylbenz(a)anthracene: comparison between RU486 and a new 21-substituted-19-nor-progestin. Oncol Rep 18(1): 167174.

Wilailak, S.\&Linasmita, V. (2004). A study of pegylated liposomal Doxorubicin in platinumrefractory epithelial ovarian cancer. Oncology 67(3-4): 183-186.

$\mathrm{Xu}, \mathrm{M}$. , Song, L.\&Wang, Z. (2003). Effects of Dexamethasone on glucocorticoid receptor expression in a human ovarian carcinoma cell line 3AO. Chin Med J (Engl) 116(3): 392-395.

Xu, Q., Takekida, S., Ohara, N., Chen, W., Sitruk-Ware, R., Johansson, E. D.\&Maruo, T. (2005). Progesterone receptor modulator CDB-2914 down-regulates proliferative cell nuclear antigen and Bcl-2 protein expression and up-regulates caspase-3 and poly(adenosine 5'-diphosphate-ribose) polymerase expression in cultured human uterine leiomyoma cells. J Clin Endocrinol Metab 90(2): 953-961.

Yaginuma, Y.\&Westphal, H. (1992). Abnormal structure and expression of the p53 gene in human ovarian carcinoma cell lines. Cancer Res 52(15): 4196-4199.

Yokoyama, Y., Shinohara, A., Takahashi, Y., Wan, X., Takahashi, S., Niwa, K.\&Tamaya, T. (2000). Synergistic effects of danazol and mifepristone on the cytotoxicity of UCN01 in hormone-responsive breast cancer cells. Anticancer Res 20(5A): 3131-3135.

Yudt, M. R., Jewell, C. M., Bienstock, R. J.\&Cidlowski, J. A. (2003). Molecular origins for the dominant negative function of human glucocorticoid receptor beta. Mol Cell Biol 23(12): 4319-4330.

Zhang, S., Jonklaas, J.\&Danielsen, M. (2007). The glucocorticoid agonist activities of mifepristone (RU486) and progesterone are dependent on glucocorticoid receptor levels but not on EC50 values. Steroids 72(6-7): 600-608.

Zhao, J., Kennedy, B. K., Lawrence, B. D., Barbie, D. A., Matera, A. G., Fletcher, J. A.\&Harlow, E. (2000). NPAT links cyclin E-Cdk2 to the regulation of replicationdependent histone gene transcription. Genes Dev 14(18): 2283-2297. 


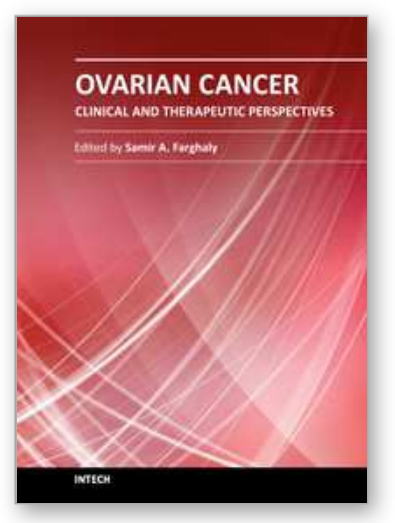

\author{
Ovarian Cancer - Clinical and Therapeutic Perspectives \\ Edited by Dr. Samir Farghaly
}

ISBN 978-953-307-810-6

Hard cover, 338 pages

Publisher InTech

Published online 15, February, 2012

Published in print edition February, 2012

Worldwide, Ovarian carcinoma continues to be responsible for more deaths than all other gynecologic malignancies combined. International leaders in the field address the critical biologic and basic science issues relevant to the disease. The book details the molecular biological aspects of ovarian cancer. It provides molecular biology techniques of understanding this cancer. The techniques are designed to determine tumor genetics, expression, and protein function, and to elucidate the genetic mechanisms by which gene and immunotherapies may be perfected. It provides an analysis of current research into aspects of malignant transformation, growth control, and metastasis. A comprehensive spectrum of topics is covered providing up to date information on scientific discoveries and management considerations.

\title{
How to reference
}

In order to correctly reference this scholarly work, feel free to copy and paste the following:

Carlos M. Telleria and Alicia A. Goyeneche (2012). Antiprogestins in Ovarian Cancer, Ovarian Cancer - Clinical and Therapeutic Perspectives, Dr. Samir Farghaly (Ed.), ISBN: 978-953-307-810-6, InTech, Available from: http://www.intechopen.com/books/ovarian-cancer-clinical-and-therapeutic-perspectives/antiprogestins-inovarian-cancer

\section{INTECH}

open science | open minds

\section{InTech Europe}

University Campus STeP Ri Slavka Krautzeka 83/A 51000 Rijeka, Croatia Phone: +385 (51) 770447 Fax: +385 (51) 686166 www.intechopen.com

\section{InTech China}

Unit 405, Office Block, Hotel Equatorial Shanghai

No.65, Yan An Road (West), Shanghai, 200040, China 中国上海市延安西路65号上海国际贵都大饭店办公楼 405 单元

Phone: +86-21-62489820

Fax: $+86-21-62489821$ 
(C) 2012 The Author(s). Licensee IntechOpen. This is an open access article distributed under the terms of the Creative Commons Attribution 3.0 License, which permits unrestricted use, distribution, and reproduction in any medium, provided the original work is properly cited. 